\title{
LEAN MANUFACTURING USED IN CONSTRUCTION MANAGEMENT
}

\section{MANAS RANJAN DAS \& BIBHUTI B PRADHAN}

Research Scholar, Department of Management, Siksha 'O' Anusandhan (Deemed to be University),

Bhubaneswar, Odisha, India

\begin{abstract}
In recent decades, the construction industry has faced internal and external pressures such as the financial crisis, the profitability of the market and the growing value of the quality needed by the customer. Since it is a sector with low productivity and high levels of waste, especially with resources such as labour, it is important to look for new management methods and regulation of production. The creation of a competitive environment aimed at minimizing waste, costs and deadlines, meeting consumer needs and increasing quality and productivity in construction sites has broken old paradigms in this field through the implementation of Lean Manufacturing practices in civil works. Throughout this way, the purpose of this research is to study the application of Lean Manufacturing and its impact on construction management, through the production of case studies on construction sites, where these principles have been implemented and the findings obtained in this research are presented.
\end{abstract}

KEYWORDS: Construction, Production Management, Lean Manufacturing

Received: Jun 08, 2020; Accepted: Jun 28, 2020; Published: Aug 26, 2020; Paper Id.: IJMPERDJUN2020908

\section{INTRODUCTION}

The construction industry is experiencing significant changes that directly affect countries ' economies, the competition and demand for quality, and thereby requiring the transfer of processes, ideas and technologies from manufacturing to the construction site [1].

Tools that permit high levels of competition and the recognition of persistent, efficient and managerial problem characteristics are currently imperative. The quest for and alternative that is cheaper, time-efficient, needs fewer raw material and manpower, reduces wasteful activities that can often lead to construction site failures[1], [2].A significant feature of the construction industry is its heterogeneous nature, which consists of a wide variety of services and technologies, serving various demands [2].

Studies conducted in different countries assessed the need for preparation, finding out that the key cause of the construction industry's low productivity levels is strongly connected with preparation and control deficiencies [1].In that sense, it is proposed that construction industry companies build the knowledge about the Lean Construction Process and the methods used by that method. The goal of the work is to establish guidelines for implementing techniques that assist in the implementation of Lean Manufacturing, approaching the planning and control of construction using technical observation and analysis. In general, the activities were identified and implemented by three separate construction firms, aiming to enhance the management, preparation and control of the building sites[3]-[5]. 


\section{MATERIALS AND METHODS}

\subsection{Lean Construction}

Lean Construction is described as a production management model in the building industry, based on the Lean Manufacturing process, which aimed to increase production efficiency levels. The Lean Construction method is the Lean Production approach used on a construction site to recognize activities that may cause workflow interruption. These activities result in waste and rework and should therefore be reduced. Project management in the Lean system-based construction industry is different from traditional practices because the outcome is a collection of clearly specified targets for the development process, the project efficiency, parallel product and process design[6]-[9], and production control over the lifespan of the project. The definition of Lean Construction was therefore established, laying down eleven principles for the application in civil construction, the ones listed below:

- Reduce the fraction of non-resulting activities-in order to enhance the operation, the losses must be minimized, thus increasing the conversion and efficiency of the workflow.

- Take into consideration the needs of the consumer in order to maximize the profitability of the product-the interests of the internal and external consumers should be taken into account in planning and manufacturing.

- Reduction of volatility-manufacturing processes are not inherently predictable and have different resource needs (time, workforce and raw materials), even though the end product is the same.

- Reduction of cycle time-a collection of all cycles linked to materials, necessary for building. Reducing cycle time refers to the provision of each phase in the right time, preventing the creation of big stocks.

- Simplify by reduction of steps, sections and connections-simplification of the process can be achieved by rejecting the useful steps or sections and removing redundant tasks. The methods used to achieve process simplification include the use of prefabricated components, multidisciplinary team, and implementation of 5Sstyle software, efficient process planning, and others.

- Increasing the reliability of the tests-it's increasing the adjustment potential

- Through consistency in the process-the more open a process is, the easier it is to provide better monitoring and improvements. Transparency decreases the risk of errors, improves the overall visibility of production, and promotes improvements.

- Global process control emphasis-the segmented process control has its trans current workflow across various units or through an organization.

- Implementation of continuous process improvement-continuous process improvement eliminates costs and increases the value of the product. This is an internal mechanism, with strong employee involvement, which, along with other programs, will receive efficiency, contributing to continuous improvement of the mechanism.

- Workflow balancing through improved conversion-workflows and conversion should be prioritized in order to improve efficiency, because different features have to be found in each production phase. Generally speaking, the more complex a step is, the more inherent residues are produced, giving more room for improvement through modification of the workflow. 
- Benchmarking-it is the procedure of the productive organizations to implement procedures and processes. It is a easy method that is less costly of investment. This reduces competition, generating a pattern of methods and processes between same-economy companies.

The Figure 1 below refers to the conventional model, in which only the assembly flow is explicitly considered, having influences of For Dism.

In the Lean Construction Model, Figure 2 below, the assembly flow and other physical flows are explicitly considered: the materials flow, information and work[10]-[13].Even though those flows do not create value to the construction itself, they are a significant portion of costs and work force.

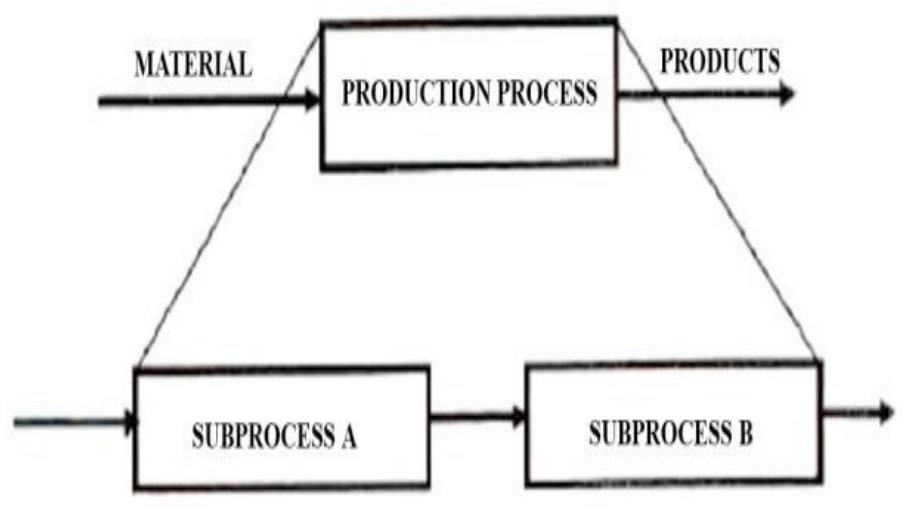

Figure 1: Conventional Process Model.

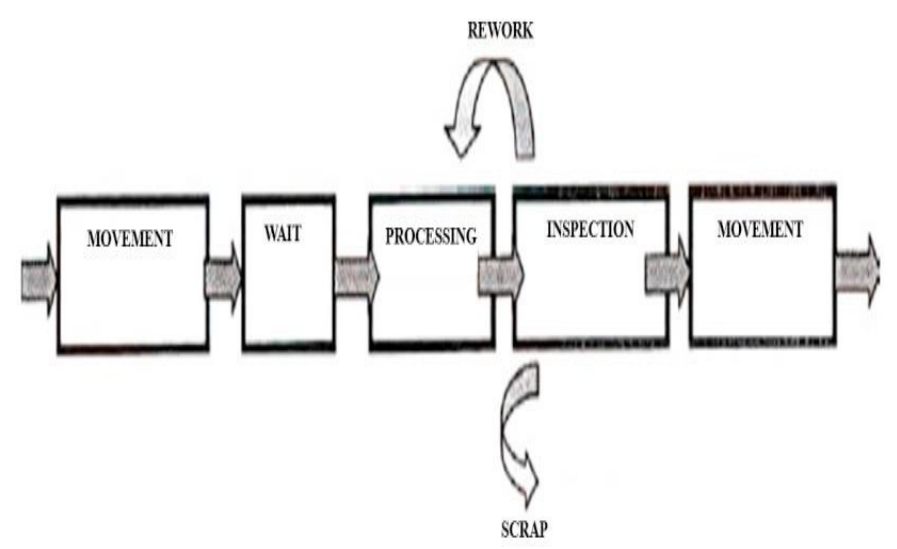

Figure 2: Lean Construction Process Model.

\subsection{Field Research:}

In order to test the application of the model to the construction industry reality, field work was conducted with three different building companies. Employees, construction and quality managers were interviewed in order to better establish a vision of the particular challenges and constraints for each company.

\section{The Field Work Followed The Following Steps:}

- Informal conversation;

- Informal interviews;

- Questionnaire;

- Periodic professional visits; 
The first phase consisted of informal, individual communication with employees of the organization.

During these interviews, the workers were asked about the construction behaviour, how they learned their profession and whether they felt able to play the same function in another way.

The second phase consisted of introducing the Lean Construction method and answering questions from employees about the concepts of each of the method's eleven principles, explaining how those principles could be implemented on the construction site. An informal interview with the staff and supervisors was performed after the process was revealed. You will find the questions posed below:

- Have you ever learned or heard of the Lean Build process before?

- Do you consent to the values being applied here on the building site?

The third stage started after the interview, using the eleven concepts, through the application of the process. The fourth stage consisted of testing the tool's application through regular construction site visits. Upon completion of the building, the site manager repeated the questionnaire on the eleven values, in which we can check the outcomes of the system implementation and the changes achieved.

\section{Procedure Workflows Are Demonstrated In Figure 3, Down Below.}

After the questionnaire was applied, an action plan started: • Meetings room (a particular location was selected so that the meetings would not interfere with the daily activities).

- Map with Lean Construction 11 principles (a map based on the results obtained in the questionnaire was drawn up, thus allowing the auditor to document the findings of the audit in a clear manner for all staff).

- Daily audits (the foreman and the engineer carried out routine audits, and the results were reported in the 11principle chart).

- Regular meetings before operation commencement (regular meetings were held to evaluate the performance of the previous day and address progress

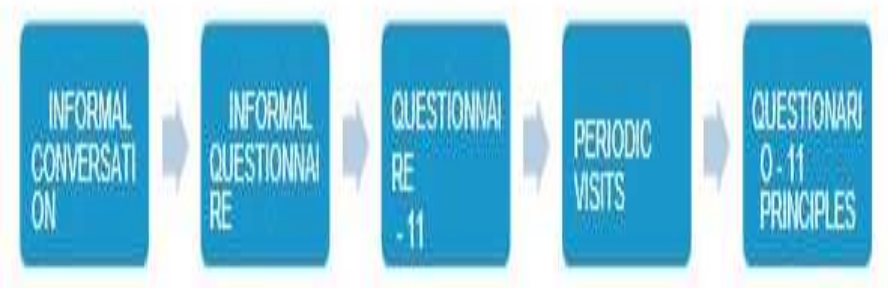

Figure 3: Workflow of the Procedure.

\section{RESULTS}

When introducing the method and holding the informal interview with the managers and staff, only the managers claimed that they had already learned of the "Lean Building" method but still did not know it, because everyone agreed to start implementing the concepts in the work. The first study, performed with the three builders ' staff, was achieved through the 
informal dialogs, in which the questionnaire of the 11 Lean Manufacturing / Construction concepts was applied. Such questionnaires were answered with answers varying between yes and no, in order to turn the questions into statistical results, the average of the positive answers of the questionnaire was adopted (adopting one for yes and zero for no), where all the staff who worked on the construction site of both constructors answered the questionnaire, thus allowing the evaluation of the conditions before qualifying.

The following graph, illustrated by Figure 4 represents the percentage of employee responses for each of the questions asked in the applied questionnaire:

The aforementioned changes would reflect a cost savings of 9 percent for Company A, 5 percent for Company B and 7 percent for Company $\mathrm{C}$ if the approach is kept until construction is complete.

The cost reduction is mainly due to the loss of procedure and reduction of uncertainty which may require rework in the future. As a result, the productivity of the company improves and thus better prices are available for the end consumers as the quality of the service is increased due to better training of the employees.

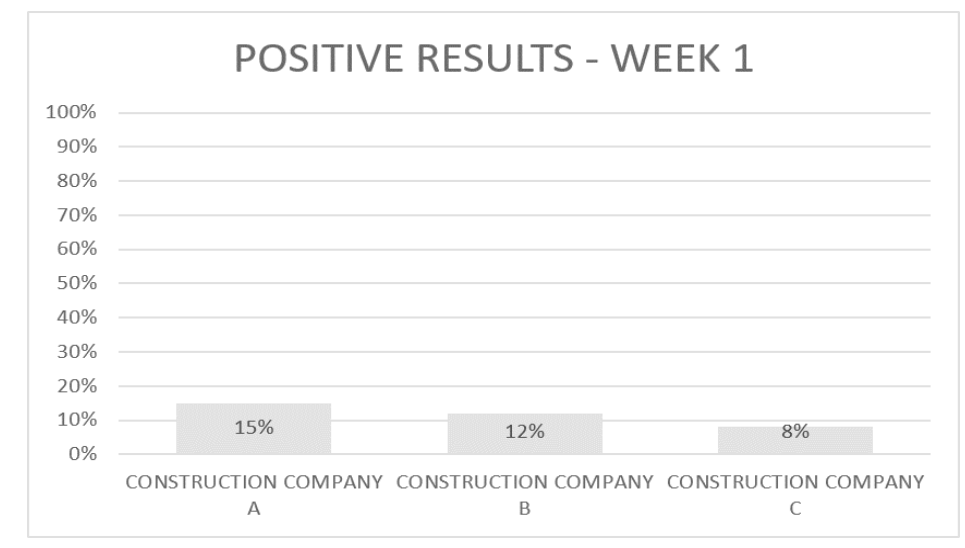

Figure 4: Search Result.

\section{CONCLUSIONS}

The study of the Lean Construction process, the questionnaire implementation and the regular visits showed significant changes as compared to the initial situation. As expected, cultural resistance could be reduced and new principles incorporated into the everyday life of the construction site and in the lives of the workers as they began to become involved in professional development.

Must be in corporate and compatible with Lean and Industry 4.0 Once combined, all these strong paradigms can help streamline processes, improve performance, and respect both company and customer. Lean's business strategies can be strengthened with the most accurate and relevant facts and statistics available at the consumer and supplier interfaces, which, in addition to reducing costs, drive real productive growth. Around the same time, these processes enable the quicker introduction of 4.0 Industry Technologies and offer greater benefits. All this, though, raises the need for those involved in technology to spend more in preparation, in preparation their own staff, to be able to make use of the resources. Finally, it can be concluded that the improvements were welcomed and that the Lean Construction process, with the requisite modifications, only brought positive results and ensured the construction success.

\section{REFERENCES}

1. G. Beitinger, “Lean manufacturing,” Plant Eng., 2012.

2. R. Sundar, A. N. Balaji, and R. M. Satheesh Kumar, "A review on lean manufacturing implementation techniques," in 
Procedia Engineering, 2014.

3. A. Sanders, C. Elangeswaran, and J. Wulfsberg, "Industry 4.0 implies lean manufacturing: Research activities in industry 4.0 function as enablers for lean manufacturing," J. Ind. Eng. Manag., 2016.

4. A. N. A. Wahab, M. Mukhtar, and R. Sulaiman, "A Conceptual Model of Lean Manufacturing Dimensions," Procedia Technol., 2013.

5. B. Mrugalska and M. K. Wyrwicka, "Towards Lean Production in Industry 4.0," in Procedia Engineering, 2017.

6. G. HOWELL and G. BALLARD, "Implementing lean construction," in Lean Construction, 2010.

7. L. Koskela, "Lean Production in Construction," in Automation and robotics in construction X: proceedings of the 10th International Symposium on Automation and Robotics in Construction (ISARC), 2017.

8. S. Gao and S. P. Low, "The Toyota Way model: An alternative framework for lean construction," Total Qual. Manag. Bus. Excell., 2014.

9. M. Poppendieck, "Principles of lean thinking," IT Manag. Sel., 2011.

10. L. H. Forbes and S. M. Ahmed, Modern construction: Lean project delivery and integrated practices. 2010.

11. L. M. Khodeir and R. Othman, "Examining the interaction between lean and sustainability principles in the management process of AEC industry,” Ain Shams Eng. J., 2018.

12. J. Meiling, F. Backlund, and H. Johnsson, "Managing for continuous improvement in off-site construction: Evaluation of lean management principles,” Eng. Constr. Archit. Manag., 2012.

13. O. Rozenfeld, R. Sacks, Y. Rosenfeld, and H. Baum, “Construction Job Safety Analysis,” Saf. Sci., 2010. 